\title{
Effect of 6 Weeks of High-Intensity Interval Training with Cinnamon Supplementation on Serum Apelin Concentration and Insulin Resistance in Overweight Boys
}

\author{
Kazemi A.* PhD, Rahmati M.1 PhD, Akhondi M. ${ }^{2} M S c$
}

*Physical Education Department, Literature \& Humanities Faculty, Vali-e-Asr University of Rafsanjan, Rafsanjan, Iran

1Physical Education Department, Literature \& Humanities Faculty, Lorestan University, Khoramabad, Iran ${ }^{2}$ Physical Education Department, Literature \& Humanities Faculty, Kerman University, Kerman, Iran

\begin{abstract}
Aims: Playing an important role in regulating glucose hemostasis, apelin might empower the correlation between any increase in the adipose tissue mass and obesity and the correlated metabolic diseases. The aim of this study was to investigate the effects of 6 -week intensive periodic massive exercises with cinnamon supplementation on the apelin serum concentration and insulin resistance in the overweight boys.

Materials \& Methods: In the semi-experimental study, 40 male overweight students were studied in Zahedan in 2014. The samples, randomly selected, were divided into four groups including exercise, exercise and supplementation, supplementation, and control. 6-week intensive periodic massive exercises were done in the exercise groups. In addition, three 380mgcinnamon capsules were administrated in the supplementation groups. Blood sampling was done from the subjects 48 hours before and after the exercise program. Apelin, glucose, and insulin levels were measured. Data was analyzed by SPSS 19 software using one-way and two-way ANOVA tests and covariance analysis.

Findings: There were significant differences between "exercise" and "exercise and supplementation" groups and "control" group in apelin and insulin resistance levels after the exercise program $(p=0.0001)$. In addition, there was a significant difference between "cinnamon supplementation" and "control" groups in insulin resistance $(p=0.001)$. There were significant differences between the exercise groups and supplementation group in apelin $(p=0.0001)$ and insulin resistance $(\mathrm{p}=0.003)$ levels.

Conclusion: The serum apelin level and the insulin resistance index in the overweight boys are reduced by 6-week intense periodic massive exercises. In addition, the cinnamon supplementation only reduces the insulin resistance index.
\end{abstract}

\section{Keywords}

Insulin Resistance [http://www.ncbi.nlm.nih.gov/mesh/68007333];

Overweight [http://www.ncbi.nlm.nih.gov/mesh/68050177];

Apelin [http://www.ncbi.nlm.nih.gov/mesh/67115436];

Cinnamomum zeylanicum [http://www.ncbi.nlm.nih.gov/mesh/68002935]

\footnotetext{
* Corresponding Author

Tel: +983431312102

Fax: +983431312102

Address: Physical Education Department, Faculty of Literature \& Humanities, Vali-e-Asr University of Rafsanjan, Imam Khomayni Square, Rafsanjan, Kerman, Iran. Post Box: 518

a.kazemi@vru.ac.ir

Received: August 6, $2015 \quad$ Accepted: May 11, 2016 ePublished: June 30, 2016
} 


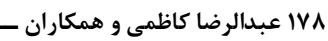

مقدمه

جاقى، مهرترين مشكل سلامتى در كشورهاى توسعهيافته و در حال توسعه است و مىتواند خطر ابتلا به بيمارىهاى مختلف از

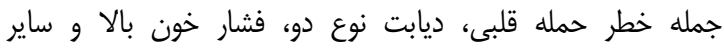

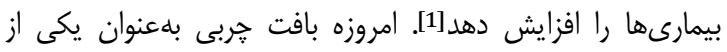
اندامهاى فعال متابوليك درونريز شناخته شده است[2]. تعدادى از

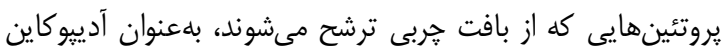

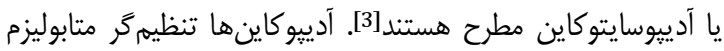

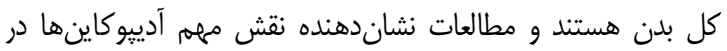
عوارض مرتبط به خاقى نيز هستند[3]. غلظت بالاى آدييوكاينها

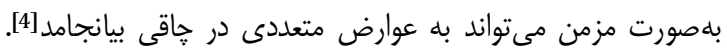
افزايش مقادير خونى اين آدييوكاينها نشاندهنده مبارزه در برابر

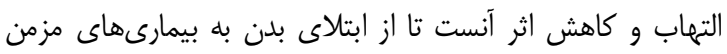
جلوگيرى كنند. در واقع افزايش مقادير خونى آنها يكى ياسخ محافظت كننده از بدن در برابر بيمارىهاست [5].

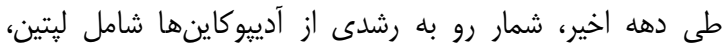

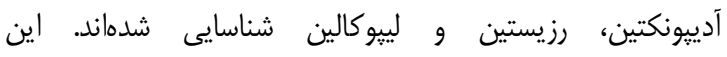

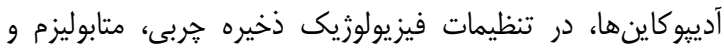

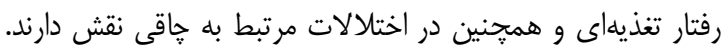

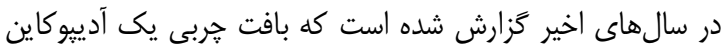
بلنام آيلين ترشح مى كند كه در متابوليزم كربوهيدرات و و عملكرد

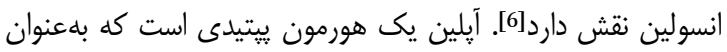

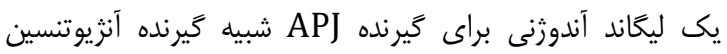

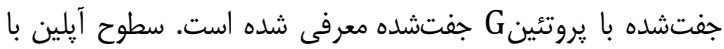

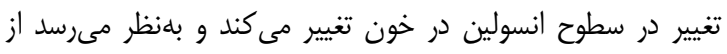

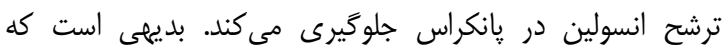

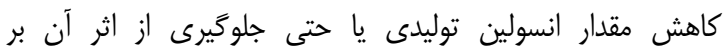

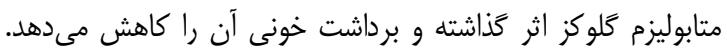

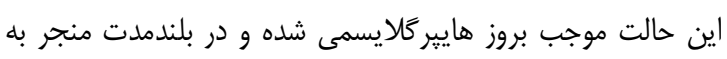
ابتلاى ديابت نوع دو مى شودد.

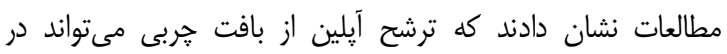

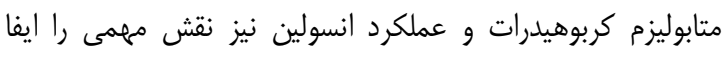

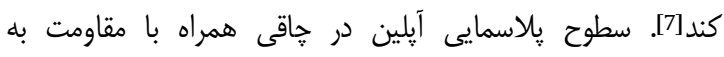

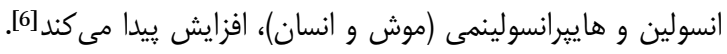

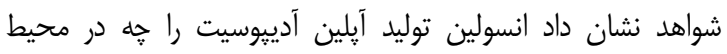
طبيعى و خه در محيط مصنوعى برمىانخيزد و سطوح آيلين با تغيير

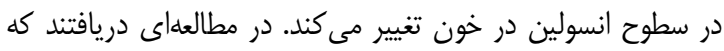

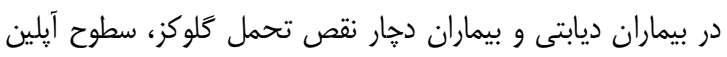

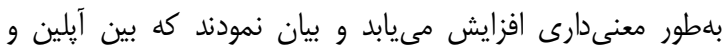
بيمارىزايى مقاومت به انسولين و ديابت نوع دو رابطه بالقوهاى دئ دئي

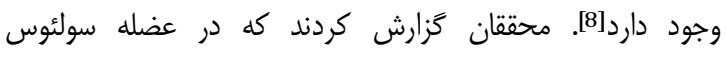
موشهاى مبتلا به كمبود آيلين، حساسيت انسولينى كاهش مى يابد.

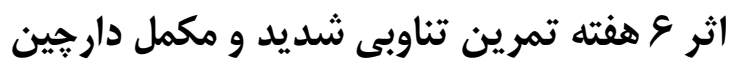
بر غلظت سرمى آيلين و مقاومت به آنس انسولين يسران داراى اضافه وزن

PhD عبدالرضا كاظمى

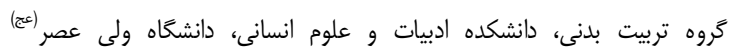
رفسنجان، رفسنجان، ايران

مسعود رحمتى مhD

كروه تربيت بدنى، دانشكده ادبيات و علوم انسانى، دانشگاه لرستان، خرم آباد،

ايران

MSc معصومه آخوندى كروه فيزيولوزى ورزشى، دانشكده ادبيات و علوم انسانى، دانشخاه كرمان، كرمان،

جكيده

اهداف: آيلين، نقش مهمى در تنظيهم هموستاز كلوكز ايفا مىكند و

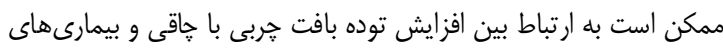

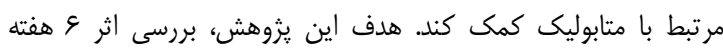

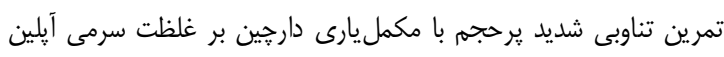

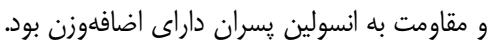

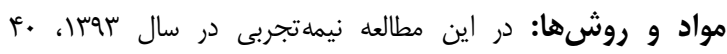

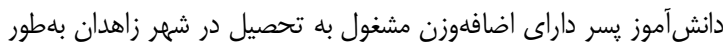

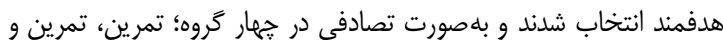

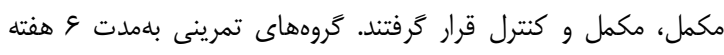

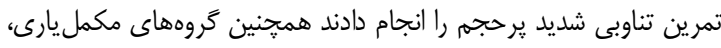

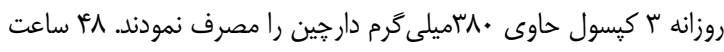

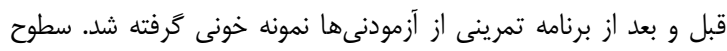

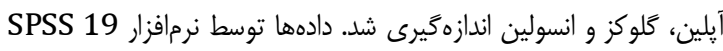

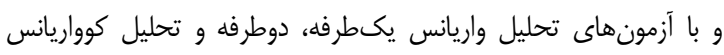

تحليل شدند.

يافتهها: بعد از دوره تمرينى، در سطوح آيلين و مقاومت انسولين

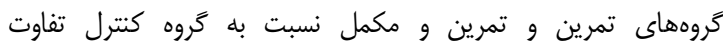

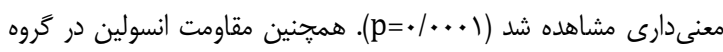

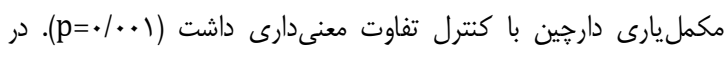

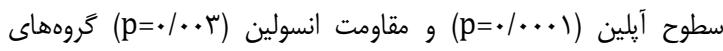
تمرينى نسبت به گروه مكمل نيز تفاوت معنى دارى مشاهده شد.

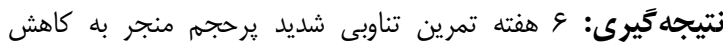

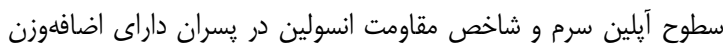

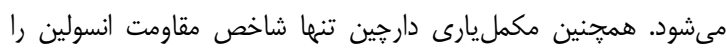
كاهش مى دهد. كليدوازهها: مقاومت به انسولين، اضافهوزن، آِيلين، دارجين

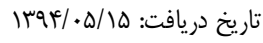

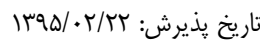

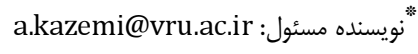




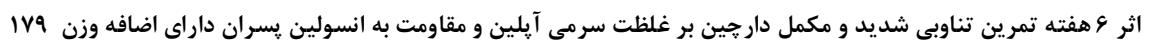

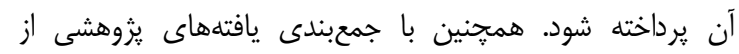

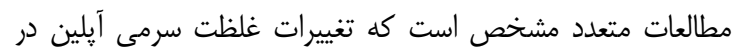

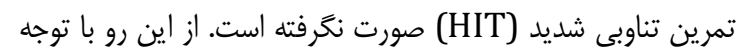

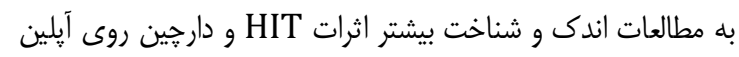

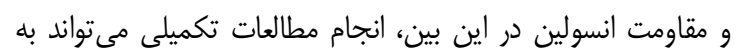
تبيين بهتر موضوع كمك نمايد. بر اين اساس، هدف از اين يروهش، برائ برسى اثر 9 هفته تمرين

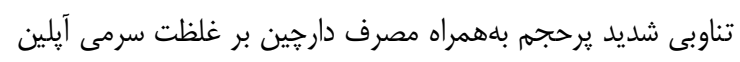
و مقاومت به انسولين پِّران داراى اضافهوزن بودم.

\section{مواد و روشها}

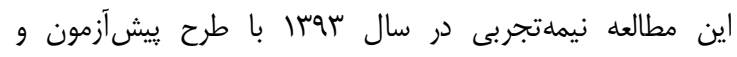

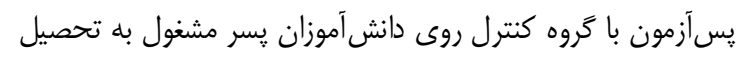

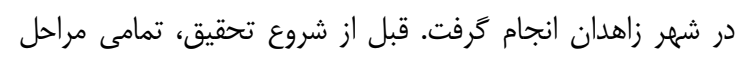

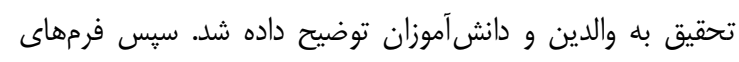

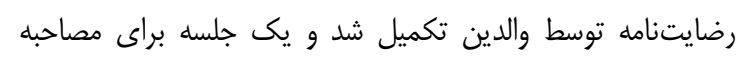

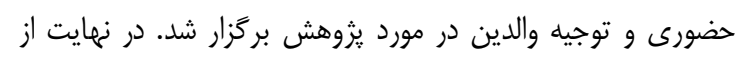

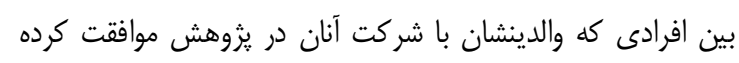

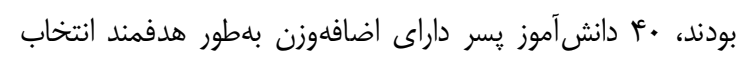

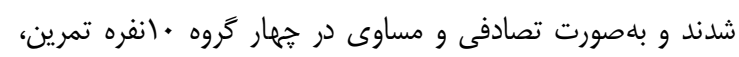
تمرين و مكمل، مكمل و كنترل قرار كرفتند.

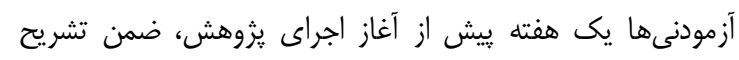

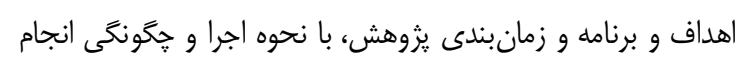

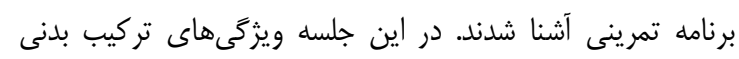

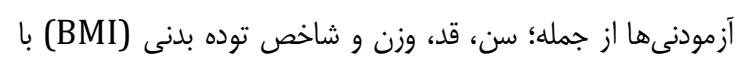

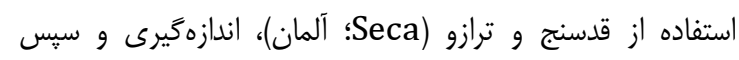

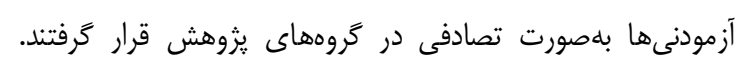

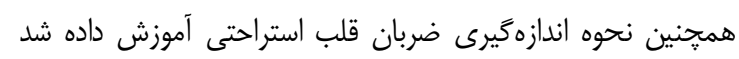

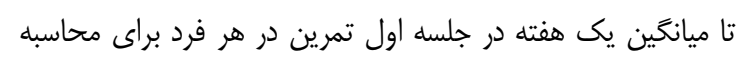

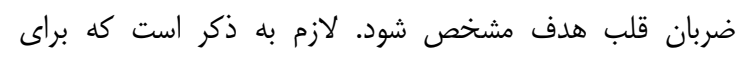
محاسبه ضربان قلب بيشينه از فرمول تاناكا و همكاران استفاده

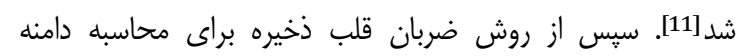
ضربان قلب هدف استفاده شد [12].

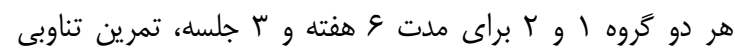

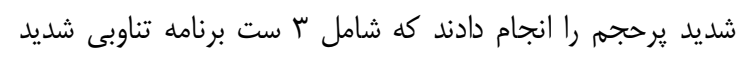

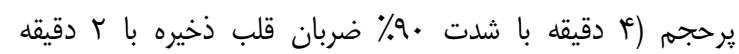

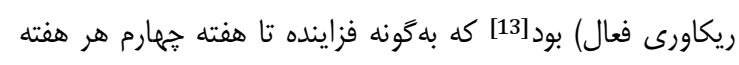

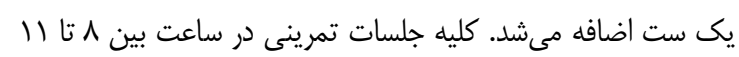

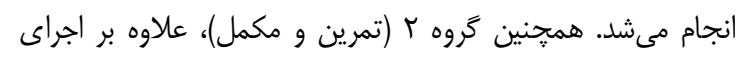

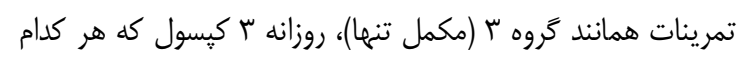

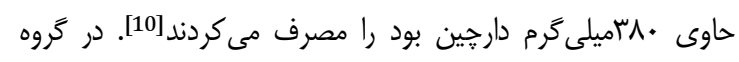

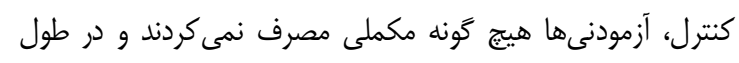

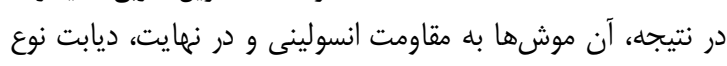

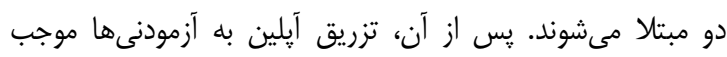

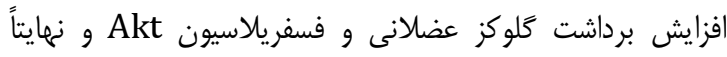

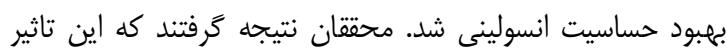

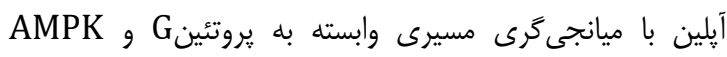

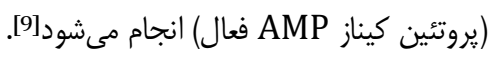

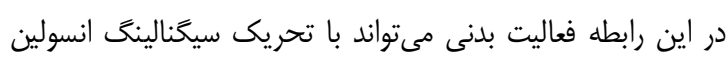

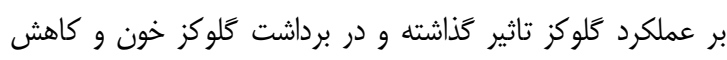

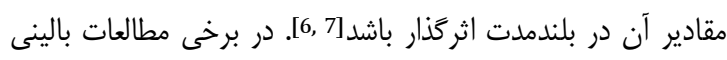

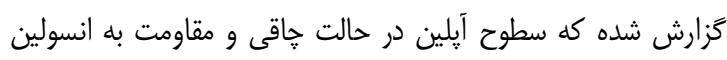

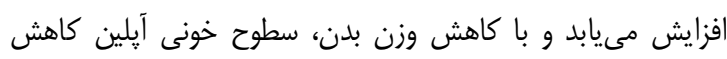

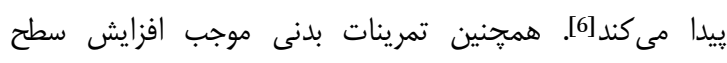

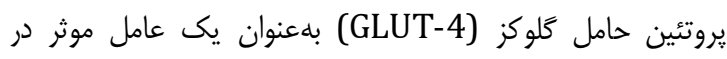

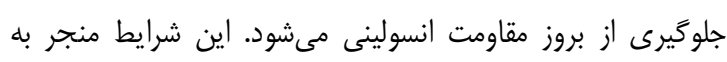

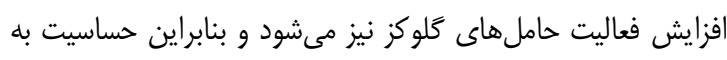

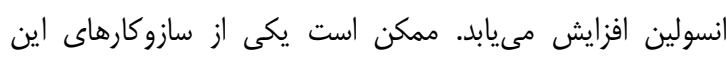

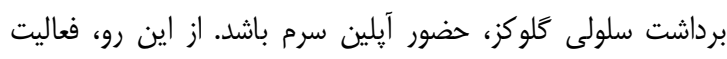

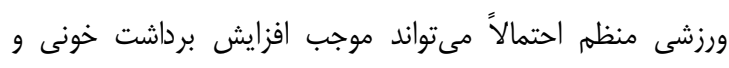

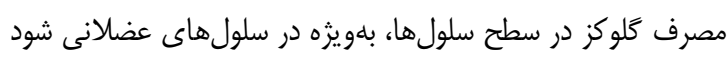

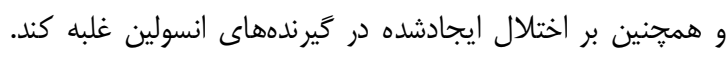

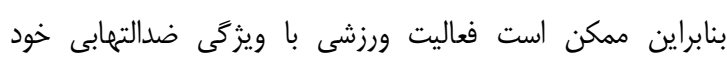

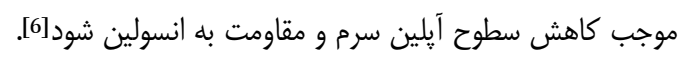

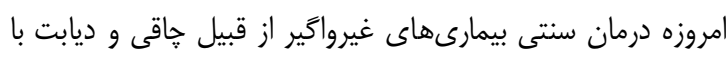

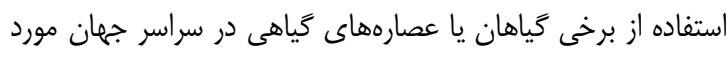

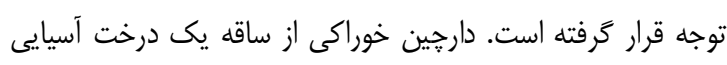

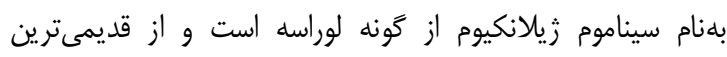

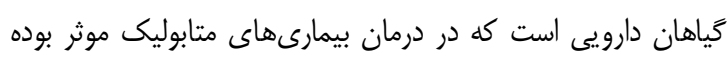

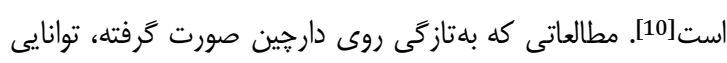

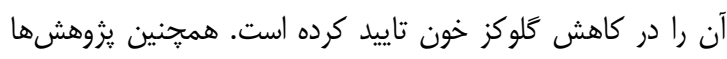

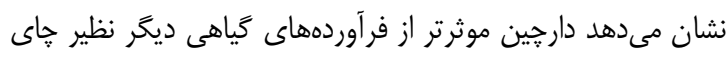

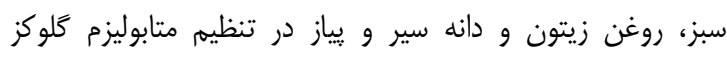

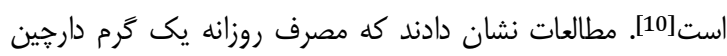

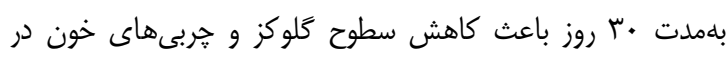
بيماران ديابتى مىشود.

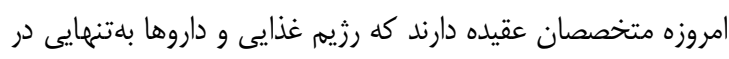

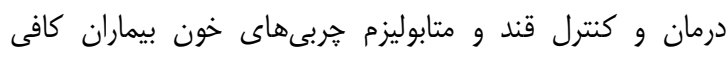

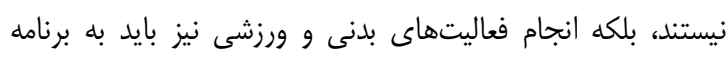

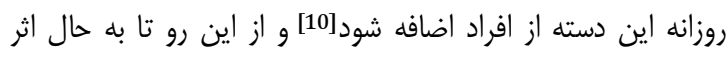

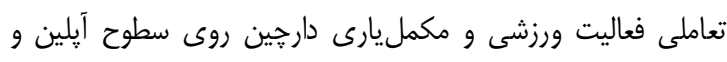

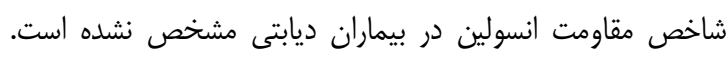

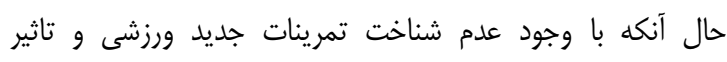

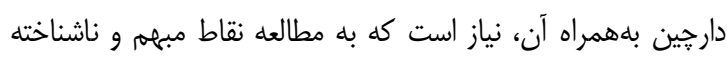


نداشتند. بعد از دوره تمرينى، تفاوت معنىدارى در سطوح آيلين

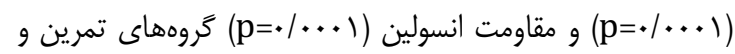

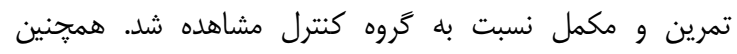

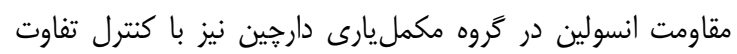

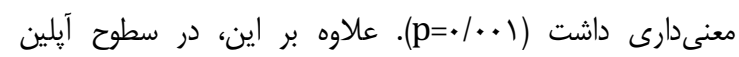
(p=•/.+1)

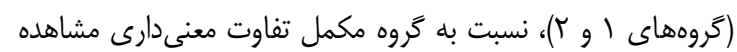

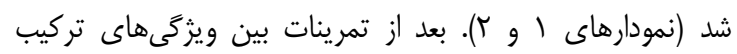

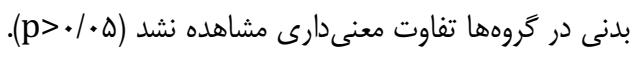

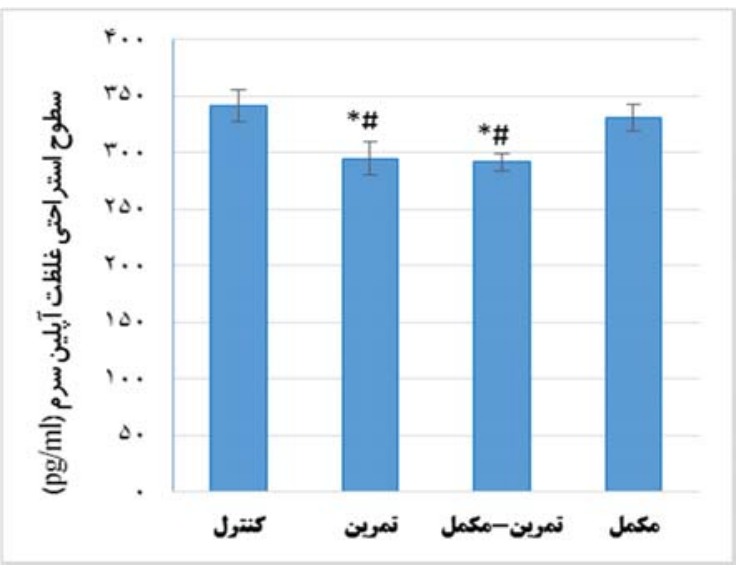

نمودار () مقايسه سطوح آيلين سرم كروهها بعد از تمرينات (*تفاوت معنىدار

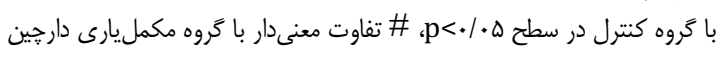
$(\mathrm{p}<+/ \cdot \Delta$

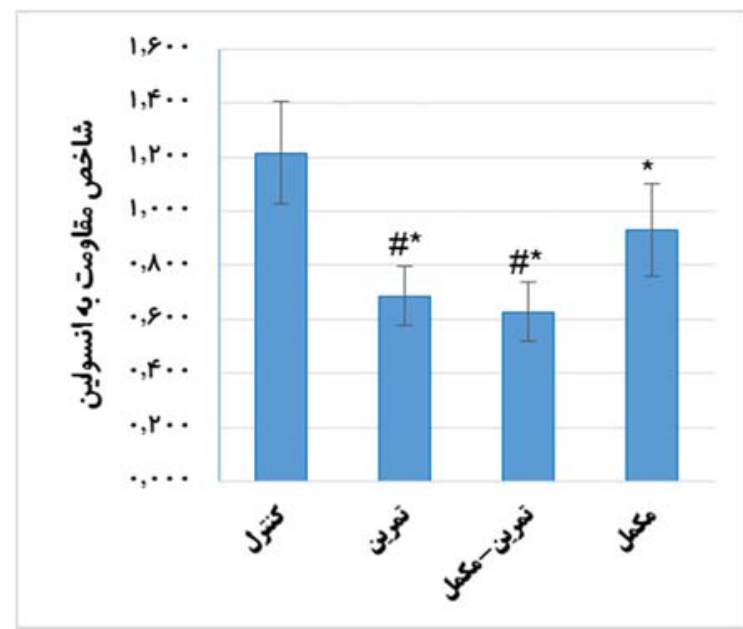

نمودار ك) مقايسه شاخص مقاومت انسولين كروهها بعد از تمرينات (*تفاوت

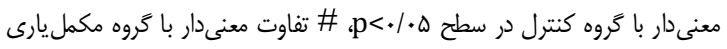
(

\section{بحث}

در مطالعه حاضر، تاثير 9 هفته تمرين تناوبى شديد برحجم و و

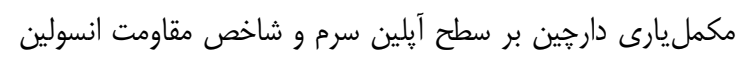

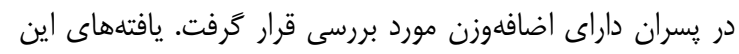

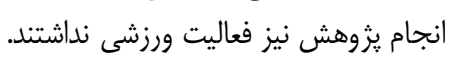

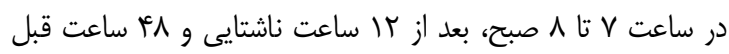

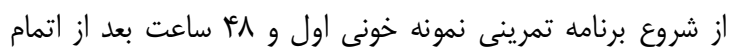

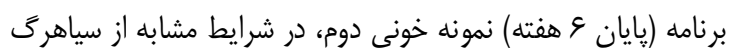

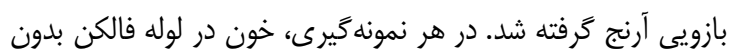

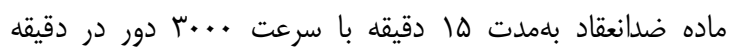

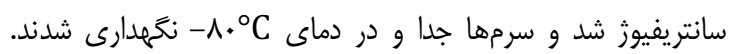

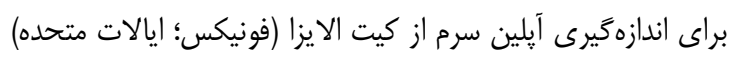

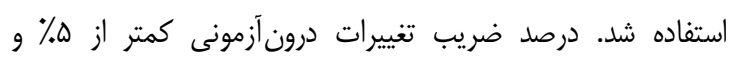

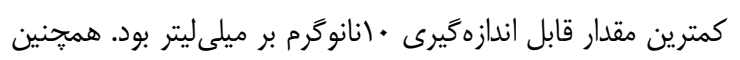

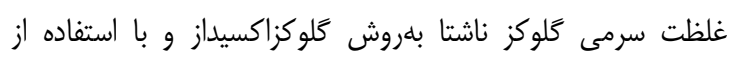
آناليزور كلوكز بكمن (Beckman Instruments)

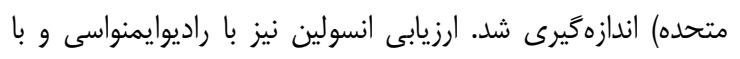

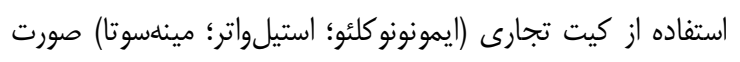

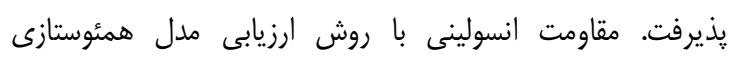

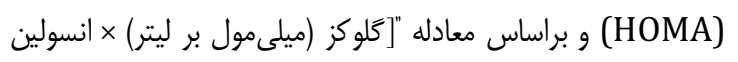

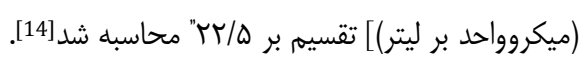

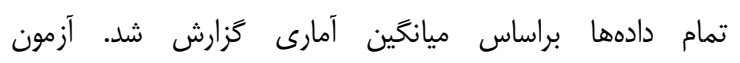

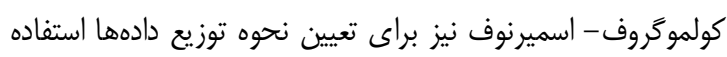

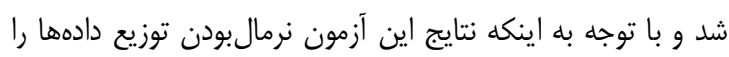

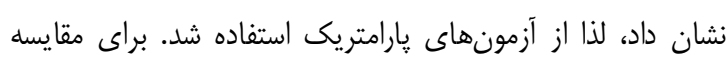

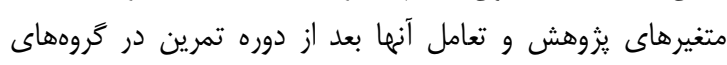

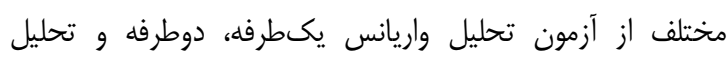

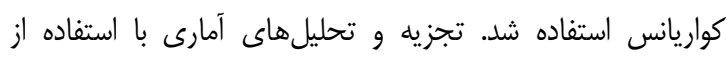

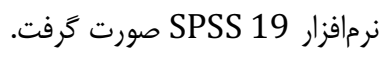

يافتهها

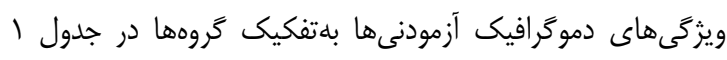

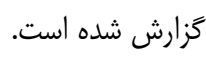

جدول () ويثَى هاى فردى آزمودنىها بهتفكيك كَروهاى يُوهش (هر كَروه برابر · م نفر)

\begin{tabular}{|c|c|c|c|}
\hline تروه تمرين و مكمل & كروه تمرين & تَروه مكمل & تروه كنترل \\
\hline$I V / \Delta \cdot \pm \cdot / \Delta T$ & $|V / T \cdot \pm \cdot| q T$ & $|V / F \cdot \pm \cdot| \Delta \mid$ & 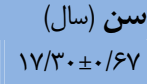 \\
\hline $\mid q N / A \cdot \pm g / \cdot \Delta$ & $\mid \Phi \mathrm{V} / \Lambda \cdot \pm \Delta / \mathrm{r} \Lambda$ & $\mid V T / r \cdot \pm \varepsilon / F \Lambda$ & 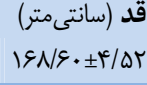 \\
\hline$\Lambda \Gamma / g \cdot \pm \Lambda / V r$ & $\Lambda \cdot / \Lambda \cdot \pm 1 \cdot / \pi r$ & 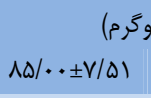 & 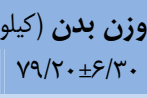 \\
\hline 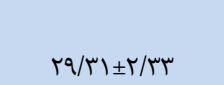 & 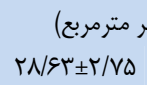 & 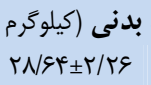 & 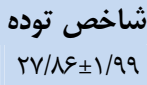 \\
\hline
\end{tabular}

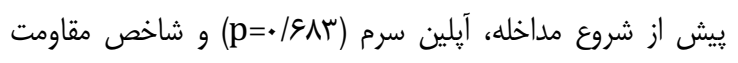

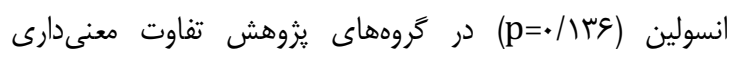
دوره זr، شماره r، تابستان هوسו فصلنامه افق دانش 


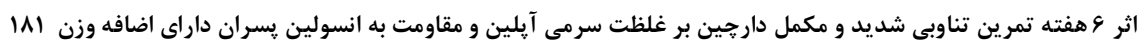

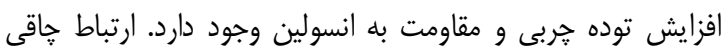

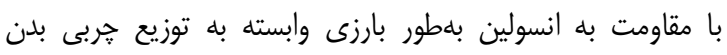

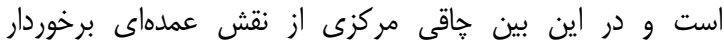

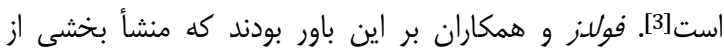

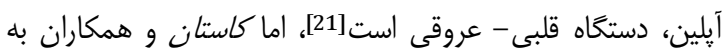

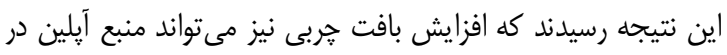

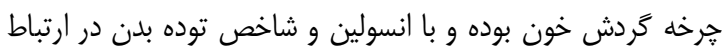

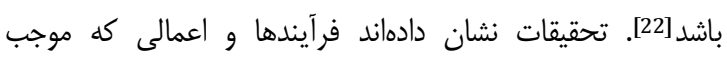

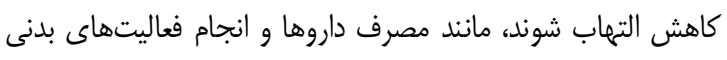

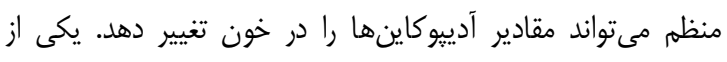

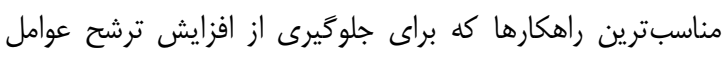

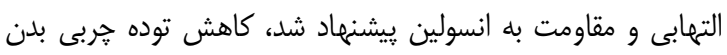

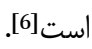

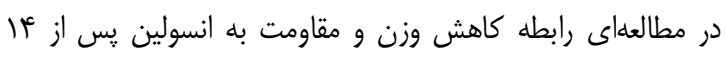

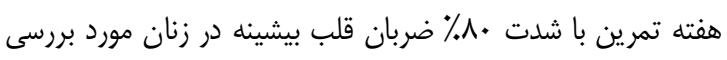

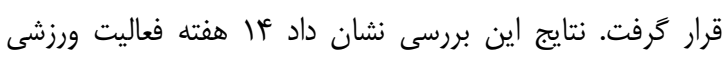

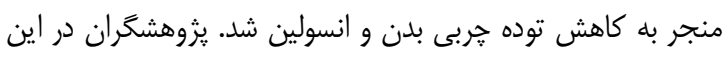

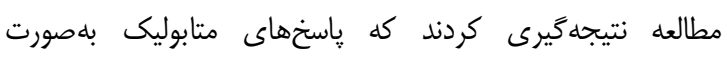

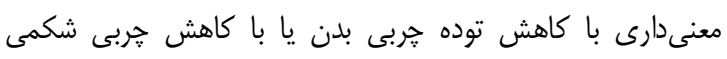
همبستخى دارد[23].

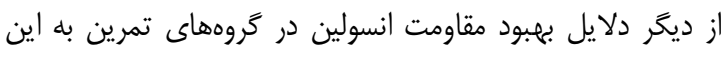

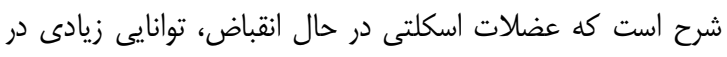

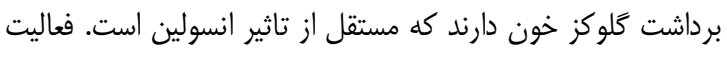

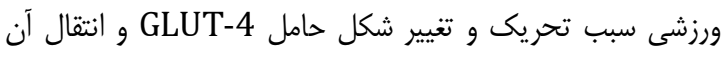

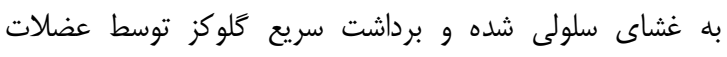

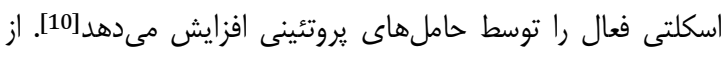

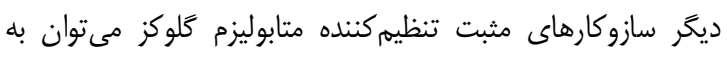

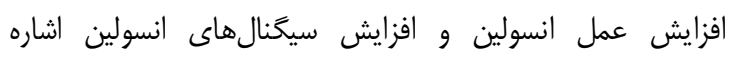

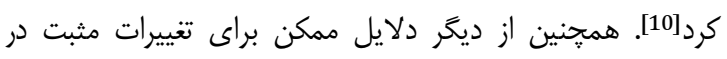

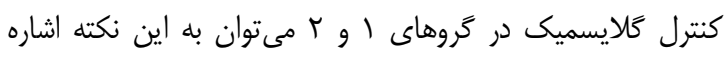

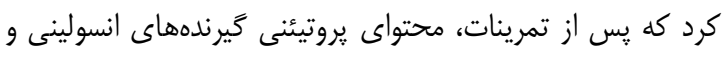

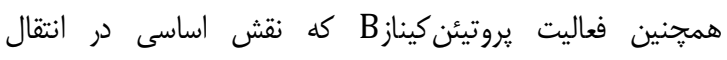

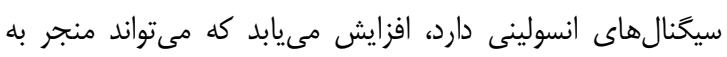

كاهش كلوكز خون افراد شود [10].

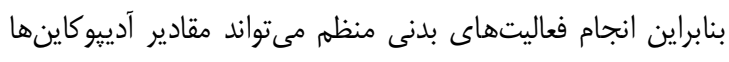

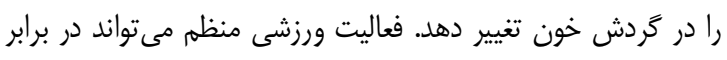

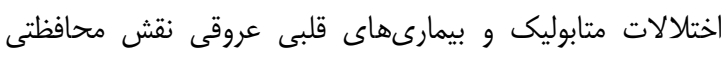

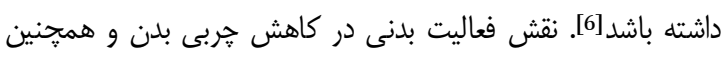

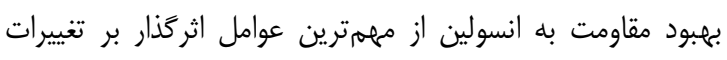

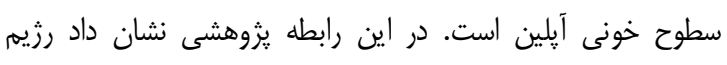

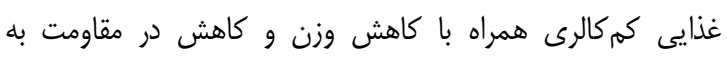

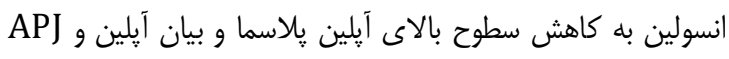

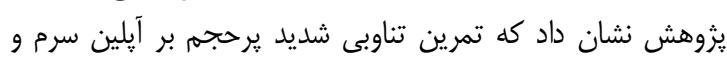

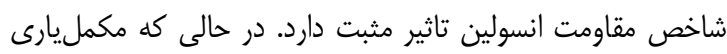

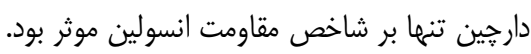

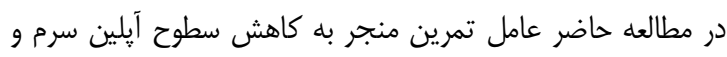

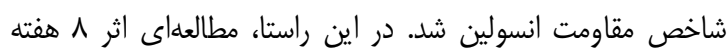

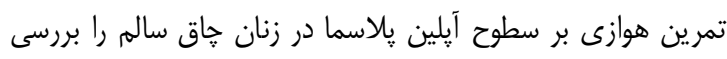

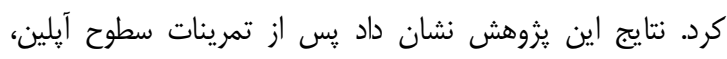

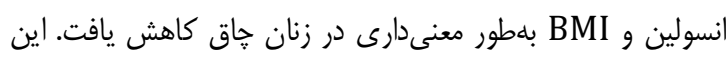

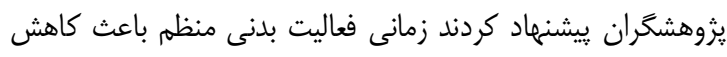

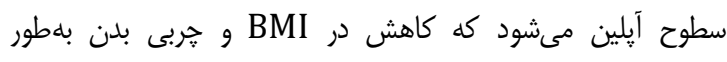

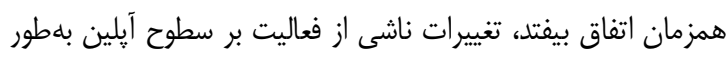

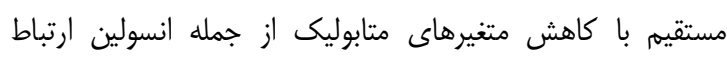

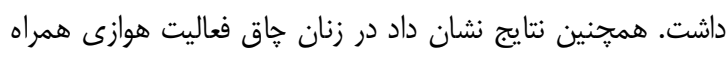

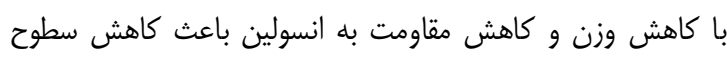

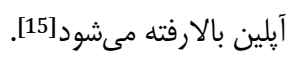

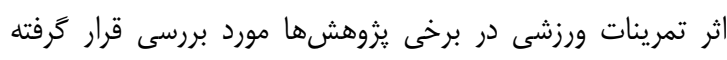

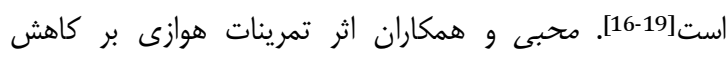

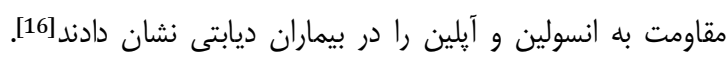

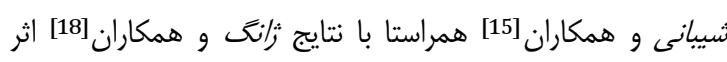

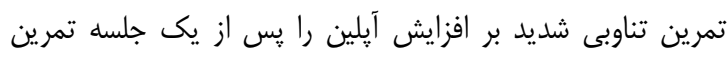

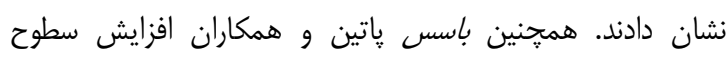

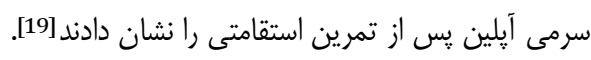

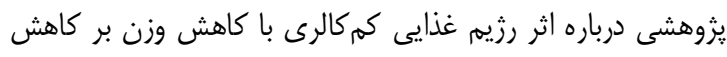

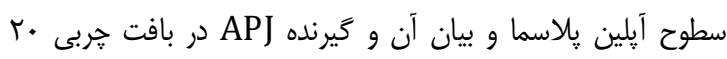

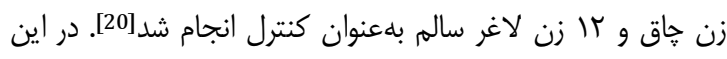

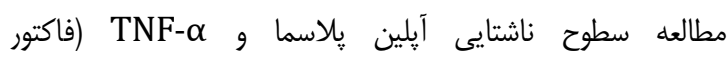

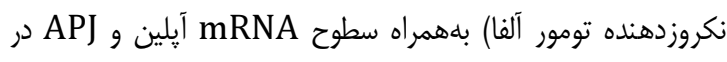

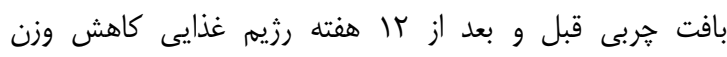

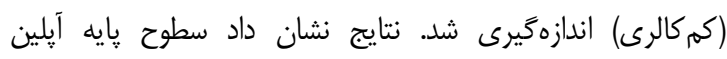

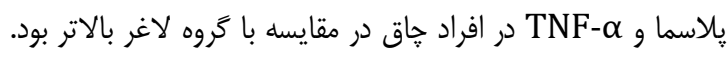

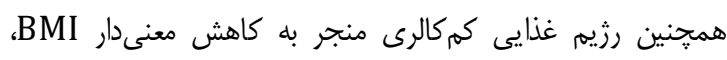
آيلين،

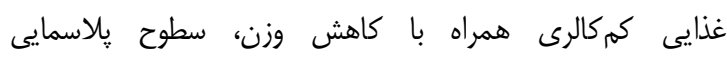

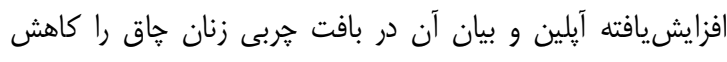

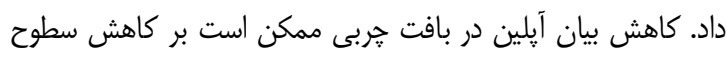

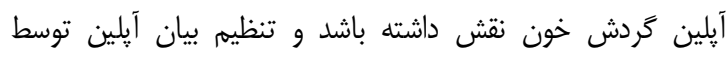
انسولين و TNF-

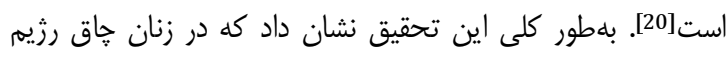

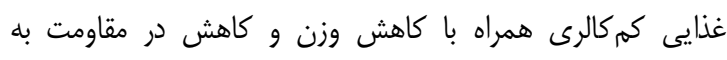

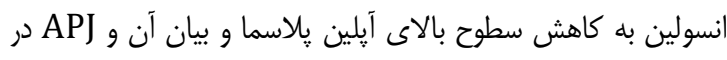

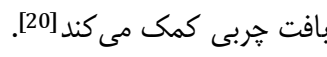
در رابطه با مقاومت انسولين بايد بيان كرد كه يك ييوند كليدى بين 


\section{منابع}

1- Aminilari Z, Daryanoosh F, Koshkie Jahromi M, Mohammadi M. The effect of 12 weeks aerobic exercise on the apelin, omentin and glucose in obese older women with diabetes type 2. Arak Med Univ J. 2014;17(4):1-10. [Persian]

2- Otero M, Lago Ro, Lago F, Casanueva FF, Dieguez C, Gómez-Reino JJ, et al. Leptin, from fat to inflammation: Old questions and new insights. FEBS Letters. 2005;579(2):295-301.

3- Hoffstedt J, Arvidsson E, Sjölin E, Wåhlén K, Arner P. adipose tissue adiponectin production and adiponectin serum concentration in human obesity and insulin resistance. J Clin Endocrinol Metab. 2004;89(3):1391-6.

4- Berg AH, Combs TP, Du X, Brownlee M, Scherer PE. The adipocyte-secreted protein Acrp30 enhances hepatic insulin action. Nat Med. 2001;7(8):947-53.

5- Yamauchi T, Kamon J, Waki H, Terauchi Y, Kubota N, Hara $\mathrm{K}$, et al. The fat-derived hormone adiponectin reverses insulin resistance associated with both lipoatrophy and obesity. Nat Med. 2001;7(8):941-6.

6- Mohebbi H, Saeidi Ziabari T, Hedayati Emami MH. Changes in plasma apelin level and insulin resistance index after an aerobic exercise training in overweight healthy women. Metab Exerc. 2013;3(1):11-20. [Persian] 7- Heinonen MV, Purhonen AK, Miettinen P, Paakkonen M, Pirinen E, Alhava E, et al. Apelin, orexin-A and leptin plasma levels in morbid obesity and effect of gastric banding. Regul Pept. 2005;130(1-2):7-13.

8- Li L, Yang G, Li Q, Tang Y, Yang M, Yang H, et al. Changes and relations of circulating visfatin, apelin, and resistin levels in normal, impaired glucose tolerance, and type 2 diabetic subjects. Exp Clin Endocrinol Diabetes. 2006;114(10):544-8.

9- Yue P, Jin H, Aillaud M, Deng AC, Azuma J, Asagami T, et al. Apelin is necessary for the maintenance of insulin sensitivity. Am J Physiol Endocrinol Metab. 2010;298(1):E59-67.

10- Rashidlamir A, Alizadeh A, Ebrahimiatri A, Dastani M. The effect of four-week period of aerobic exercise with cinnamon consumption on lipoprotein indicates and blood sugar in diabetic female patients (type 2). J Shahid Sadoughi Univ Med Sci. 2013;20(5):605-14. [Persian]

11- Tanaka H, Monahan KD, Seals DR. Age-predicted maximal heart rate revisited. J Am Coll Cardiol. 2001;37(1):153-6.

12- American College of Sports Medicine. ACSM's guidelines for exercise testing and prescription. Philadelphia: Lippincott Williams \& Wilkins; 2013. p.p. 113-5.

13- Gurd BJ, Perry CG, Heigenhauser GJ, Spriet LL, Bonen A. High-intensity interval training increases SIRT1 activity in human skeletal muscle. Appl Physiol Nutr Metab. 2010;35(3):350-7.

14- Matthews DR, Hosker JP, Rudenski AS, Naylor BA, Treacher DF, Turner RC. Homeostasis model assessment: insulin resistance and beta-cell function from fasting plasma glucose and insulin concentrations in man. Diabetologia. 1985;28(7):412-9.

15- Sheibani S, Hanachi P, Refahiat MA. Effect of aerobic exercise on serum concentration of apelin, TNFalpha and insulin in obese women. Iran J Basic Med Sci. 2012;15(6):1196-201.

16- Mohebi H, Rahmaninia F, Hedayati Emami MH, Saeidi Ziyabari T. The effect of 8 weeks moderate intensity aerobic exercise on plasma Apelin level and insulin
در بافت جربى كمك مى كند[24]. مطالعهاى ديخر در زنان جاق هاق نيز نشان داد فعاليت هوازى همراه با كاهش وزن و كاهش مقاومت بـ به

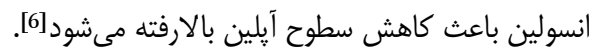

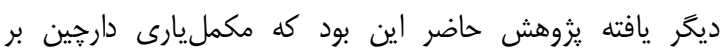

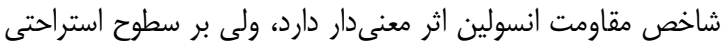
آيلين سرم تاثير نداشت. در اين رابطه رشيدالامير و همكاران نشان

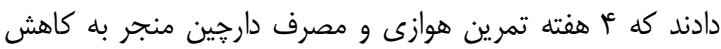

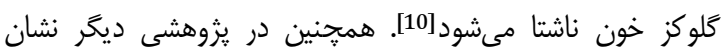

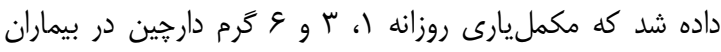

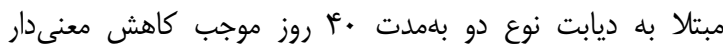
كلوكز خون ناشتا مىشود[25]. در اين رابطه مطالعات كذشته سازوكارهاى احتمالى نحوه اثر داثر

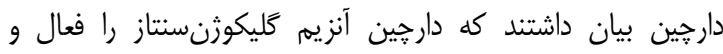

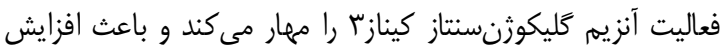
جذب كَلوكز مىشود. همجنين دارجين باعث فعالشدن كيرنداند

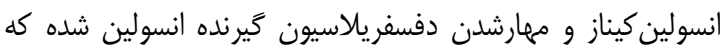
اين امر منجر به بهحداكثررسيدن فسفوريلاسيون گيرنده انسولين مىشود. تمامى اين اثرات منجر به افزايش حساسيت انسولين و

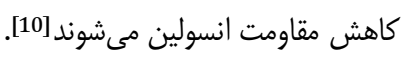

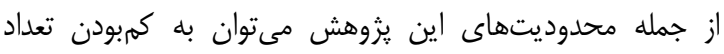

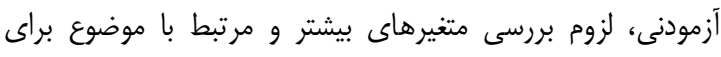

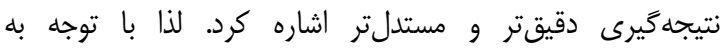
محدوديتها، نياز به انجام مطالعات بيشتر وجود دارد.

\section{نتيجه كيرى}

و هفته تمرين تناوبى شديد يرحجم منجر به كاهش سطوح آيلين

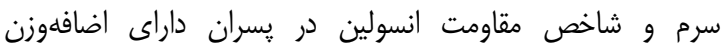
مىشود. همجنين مكمليارى دارجين تنها شاخص مقاخ مقاومت انسولين

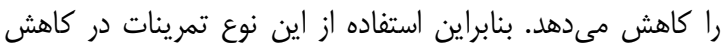
سطوح آيلين و تعامل آن با مكمليارى دارجين در كاهش شاخص آنص مقاومت انسولينى موثر است.

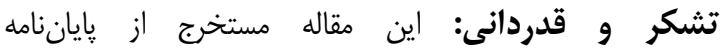
كارشناسىارشد فيزيولوزى ورزشى است. بدين وسيله از زحمات و وإنى

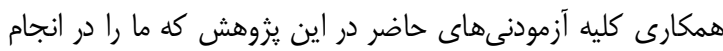
اين مطالعه يارى رساندند، كمال تقدير و تشكر راس داريم. تاييديه اخلاقى: بلمنظور ملاحظات اخلاقى تمامى مراحل

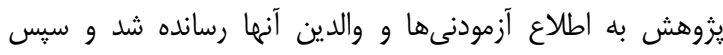

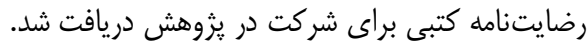
تعارض منافع: موردى توسط نويسندكان زَارش نشده است. منابع مالى: توسط نويسندًان تامين شده است.

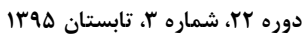

فصلنامه افق دانش مانش 


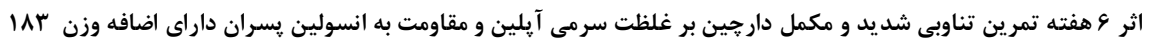

Lindstedt KA, et al. Circulating and cardiac levels of apelin, the novel ligand of the orphan receptor APJ, in patients with heart failure. Biochem Biophys Res Commun. 2003;308(3):480-5.

22- Castan-Laurell I, Vítkova M, Daviaud D, Dray C, Kováciková M, Kovacova Z, et al. Effect of hypocaloric diet-induced weight loss in obese women on plasma apelin and adipose tissue expression of apelin and APJ. Eur J Endocrinol. 2008;158(6):905-10.

23- Ross R, Janssen I, Dawson J, Kungl AM, Kuk JL, Wong $\mathrm{SL}$, et al. Exercise-induced reduction in obesity and insulin resistance in women: a randomized controlled trial. Obes Res. 2004;12(5):789-98.

24- Krist J, Wieder K, Kloting N, Oberbach A, Kralisch S, Wiesner $\mathrm{T}$, et al. Effects of weight loss and exercise on apelin serum concentrations and adipose tissue expressioninhuman obesity. Obes Facts. 2013;6(1):57-69. 25- Khan A, Safdar M, Ali Khan MM, Khattak KN, Anderson RA. Cinnamon improves glucose and lipids of people with type 2 diabetes. Diabetes Care. 2003;26(12):3215-8.

resistance in women with type 2 diabetes. Sport Physiol. 2014;5(20):115-28. [Persian]

17- Okura T, Nakata Y, Lee DJ, Ohkawara K, Tanaka K. Effects of aerobic exercise and obesity phenotype on abdominal fat reduction in response to weight loss. Int J Obes (Lond). 2005;29(10):1259-66.

18- Zhang J, Ren CX, Qi YF, Lou LX, Chen L, Zhang LK, et al. Exercise training promotes expression of apelin and APJ of cardiovascular tissues in spontaneously hypertensive rats. Life Sci. 2006;79(12):1153-9.

19-Besse-Patin A, Montastier E, Vinel C, Castan-Laurell I, Louche K, Dray C, et al. Effect of endurance training on skeletal muscle myokine expression in obese men: identification of apelin as a novel myokine. Int J Obes. 2013;38(5):707-13.

20- Castan-Laurell I, Vitkova M, Daviaud D, Dray C, Kovacikova M, Kovacova Z, et al. Effect of hypocaloric diet-induced weight loss in obese women on plasma apelin and adipose tissue expression of apelin and APJ. Eur J Endocrinol. 2008;158(6):905-10.

21- Foldes G, Horkay F, Szokodi I, Vuolteenaho O, Ilves M, 